\title{
Stereoselective Syntheses of 3-Substituted Flavene Derivatives and Asymmetric Dehydration via Kinetic Resolution
}

\author{
Min Hee Lee, Eui Ta Choi, Yoon Min Lee, Dajung Kim, and Yong Sun Park \\ Deparment of Chemistry and Bio. Holectlar Informatics Center, Konkuk Lniversity, Seoul 143-701, Korea \\ E-mail: parhyongakonkuk.ac.kr \\ Received April 2, 2008
}

Key Words : Kinetic resolıtion. Aș̣'mmetric syntheses. Chiral catalyst. Dehỵ dration. Flavonoids

The 2-phenyl-2H-chromene structural core is a widespread element in natural flavonoids and has attracted intense attention since a wide range of biological activities associated with the scaffold have been identified. ${ }^{1}$ Accordingly. the development of facile synthetic strategies to access such heterocycles is of considerable interest and a few asymmetric synthetic methods have been reported recently, ${ }^{2}$ Although the asymmetric methods could provide enantioenriched flavene derivatives. their development for more functionalized flavene skeleton has proven to be a challenging synthetic task. In this conmunication. we wish to report diastereoselective Reformatsky reaction of flavene-3-carbaldehydes to provide $\beta$-(2H-3-flavenyl)- $\beta$-hydroxy esters and disclose a new enantioselective synthetic method for 3 substituted flavene derivatives by asymmetric dehydration via kinetic resolution.

We have initially investigated the substrate controlled diastereoselective addition of Reformatshy reagent to flavene-3-carbaldehydes 1 , in which the chiral center at the $\mathrm{C}(2)$ position of $2 H$-chromene exerts control over the formation of new stereogenic center. In an initial experiment. to a solution of $\mathrm{BrZnCH}_{2} \mathrm{CO}_{2}-\mathrm{Bu}$ (3 equiv) in THF was added a solution of flavene-3-carbaldelyde 1a in THF. and the resulting mixture was heated to reflux to afford the products $2 \mathbf{a}$ and $3 \mathbf{a}$ in $91 \%$ vield with a diastereomeric ratio (dr) of 71:29. (entry 1. Table 1) Different experimental conditions have been tested on flavene-3-carbaldehyde 1a to inprove the diastereoselectivity of the addition. Since the diastereoselectivity could be enhanced by effecting the reaction at low temperature. different reaction temperatures have been tested on flavene-3-carbaldehyde 1a as sumnarized in Table 1. As the reaction temperature decreases. the $\mathrm{dr}$ is improved as shown in entries 1-5. The ratio of major $2 \mathrm{a}$ to minor product 3a was $79: 2 \mathrm{l}$ at $\mathrm{rt}$, whereas it was $90: 10$ at $-15^{\circ} \mathrm{C}$. At $-30{ }^{\circ} \mathrm{C}$, much slower reaction gave products $2 \mathbf{a}$ and $\mathbf{3 a}$ with only $15 \%$ conversion after $5 \mathrm{~h}$ and a slightly improved dr of 92:8. (entry 5) Polar solvents were then screened in an attempt to increase the solubility of the reagent and to enhance the rate and the selectivity of the reaction. The use of THF-DMSO (1:1). THF-p-dioxane (1:1) and $p$-dioxane respectively as solvent (entries 6-9) did not increase the stereoselection and decreased the vield of the reaction. Under the optinized condition at $-15^{\circ} \mathrm{C}$ in THF, the reaction of $o$-methoxy substituted flavene aldehyde $1 \mathrm{~b}$ gave slightly lower $\mathrm{dr}$ (entry 10) and p-methosy substituted flavene aldelyydes $1 c-e$ reacted with Refomatsky reagent leading to 2c-e and 3c-e with drs ranging from $89: 11$ to $91: 9$, which are practically independent on the presence of the substituents on the aromatic rings and substitution pattem. While 4chloro substituent increase the selectivity up to $94: 6 \mathrm{dr}$ (entry 16), 2-methyl substituted chromenes 1f and 1g showed much lower selectivity (entries 14-15).

Non-enzymatic kinetic resolution of racemic compounds using chiral catalyst is an area of great importance in contemporary organic synthesis. ${ }^{3}$ We recently reported the first example of the kinetic resolution in delydration of alcohols using $D$-Phg-L-Pro-derived chiral ligand $5 .{ }^{+}$Given

Table 1

\begin{tabular}{|c|c|c|c|c|c|c|c|}
\hline \multicolumn{3}{|c|}{ rac-1a-h } & & & \multicolumn{3}{|c|}{$\begin{array}{l}\text { 2a.h (major) } \\
\text { 3a-h (minor) }\end{array}$} \\
\hline Entry & S.M. & $\mathrm{X}$ & $\mathrm{Y}$ & $\mathrm{R}$ & Condition & $\begin{array}{l}\text { Yield }{ }^{4} \\
(\%)\end{array}$ & $\begin{array}{r}\mathrm{Dr}^{4} \\
(2: 3)\end{array}$ \\
\hline l & $1 \mathrm{a}$ & $\mathrm{H}$ & $\mathrm{H}$ & Ph & reflus, $05 \mathrm{~h}, \mathrm{IH}$ & 91 & $71: 29$ \\
\hline 2 & $1 \mathbf{a}$ & $\mathrm{H}$ & $\mathrm{H}$ & $\mathrm{Ph}$ & rt, l h, THF & 88 & $79: 21$ \\
\hline 3 & $1 \mathbf{a}$ & $\mathrm{H}$ & $\mathrm{H}$ & $\mathrm{Ph}$ & $0^{\circ} \mathrm{C}, 2 \mathrm{~h}, \mathrm{THF}$ & 89 & $87: 13$ \\
\hline 4 & $1 \mathbf{a}$ & $\mathrm{H}$ & $\mathrm{H}$ & $\mathrm{Ph}$ & $-15^{\circ} \mathrm{C}, 5 \mathrm{~h}, \mathrm{THF}$ & 81 & $90: 10$ \\
\hline 5 & 1a & $\mathrm{H}$ & $\mathrm{H}$ & $\mathrm{Ph}$ & $-30^{\circ} \mathrm{C}, 5 \mathrm{~h}, \mathrm{THF}$ & 11 & $92: 8$ \\
\hline 6 & 1a & $\mathrm{H}$ & $\mathrm{H}$ & $\mathrm{Ph}$ & $\begin{array}{c}\text { rt, } 2 \text { h, } \\
\text { THF+DMSO }\end{array}$ & 50 & $78: 22$ \\
\hline 7 & 1a & $\mathrm{H}$ & $\mathrm{H}$ & Ph & $\begin{array}{c}\mathrm{It}, 2 \mathrm{~h} \\
\mathrm{THF}+p \text {-Dioxane }\end{array}$ & 52 & $78: 22$ \\
\hline 8 & 1a & $\mathrm{H}$ & $\mathrm{H}$ & Ph & $\mathrm{rt}, 2 \mathrm{~h}, p$-Dioxane & 61 & $83: 17$ \\
\hline 9 & 1a & $\mathrm{H}$ & $\mathrm{H}$ & Ph & $\begin{array}{l}-15^{\circ} \mathrm{C}, 6 \mathrm{~h} \\
\mathrm{THF}+\mathrm{DMSO}\end{array}$ & 50 & $85: 15$ \\
\hline 10 & lb & $6-\mathrm{Cl}$ & $\mathrm{H}$ & $\mathrm{MeO}-\mathrm{Ph}$ & $-15^{\circ} \mathrm{C}, 5 \mathrm{~h}, \mathrm{THF}$ & 80 & $85: 15$ \\
\hline 11 & lc & $6-\mathrm{Cl}$ & $\mathrm{H}_{f}$ & $\mathrm{MeO}-\mathrm{Ph}$ & $-15^{\circ} \mathrm{C}, 5 \mathrm{~h}, \mathrm{THF}$ & 77 & $89: 11$ \\
\hline 12 & 1d & $6-\mathrm{MeO}$ & $\mathrm{H}_{\mathrm{f}}$ & $\mathrm{MeO}-\mathrm{Ph}$ & $-15^{\circ} \mathrm{C}, 5 \mathrm{~h}, \mathrm{THF}$ & 79 & $91: 9$ \\
\hline 13 & le & $8-\mathrm{MeO}$ & $\mathrm{H}_{\mathrm{f}}$ & $\mathrm{MeO}-\mathrm{Ph}$ & $-15^{\circ} \mathrm{C}, 5 \mathrm{~h}, \mathrm{THF}$ & 85 & $89: 11$ \\
\hline 14 & lf & $\mathrm{H}$ & $\mathrm{H}$ & $\mathrm{CH}_{3}$ & $-15^{\circ} \mathrm{C}, 5 \mathrm{~h}, \mathrm{THF}$ & 77 & $74: 26$ \\
\hline 15 & $1 g$ & $6-\mathrm{MeO}$ & $\mathrm{H}$ & $\mathrm{CH}_{3}$ & $-15^{\circ} \mathrm{C}, 5 \mathrm{~h}, \mathrm{THF}$ & 72 & $74: 26$ \\
\hline 16 & lh & $\mathrm{H}$ & $\mathrm{Cl}$ & $\mathrm{Ph}$ & $-15^{\circ} \mathrm{C}, 5 \mathrm{~h}, \mathrm{THF}$ & 81 & $94: 6$ \\
\hline
\end{tabular}

${ }^{a}$ Isolated yields. ${ }^{b} \mathrm{The}$ drs are detemined by ${ }^{1} \mathrm{H}$ NMR of reaction mixture. 

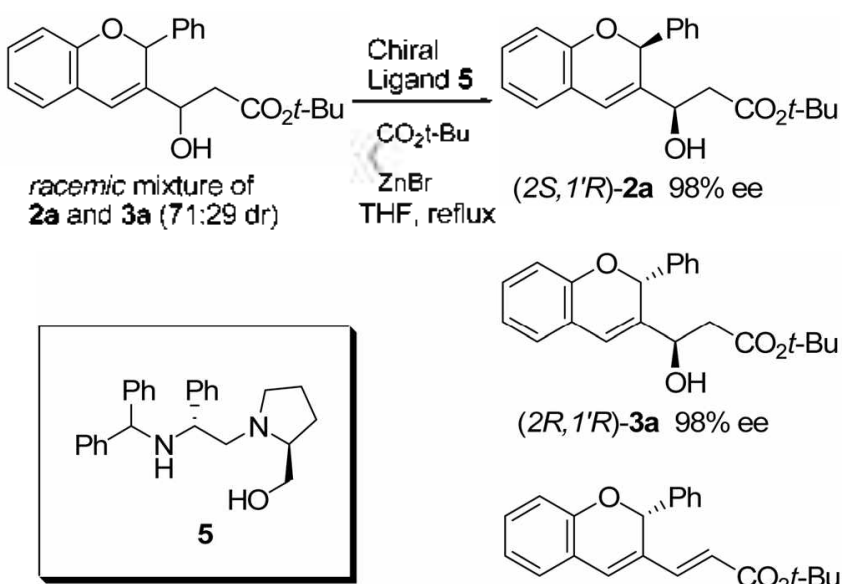<smiles>CC(C)(C)OC(=O)C[C@H](O)C1=Cc2ccccc2O[C@H]1c1ccccc1</smiles>

$\left(2 R, 1^{\prime} R\right)-3 \mathbf{a} 98 \%$ ee<smiles>CC(C)(C)OC(=O)/C=C/C1=Cc2ccccc2O[C@H]1c1ccccc1</smiles>

(2R)-4a $40 \%$ ee

Scheme 1

the high levels of selectivity attainable in the asymmetric dehydration of $\beta$-aryl or alkenyl $\beta$-hydroxy esters with chiral ligand 5 , we evaluated whether $\beta$ - $(2 H$-3-flavenyl $)-\beta$ hydroxy esters 2 and 3 . which bear an additional stereogenic center. might be good candidates for kinetic resolution with the chiral ligand. When the diastereomeric mixture of racenic 2a and $3 \mathrm{a}(71: 29 \mathrm{dr})$ was treated with $\mathrm{BrZnCH}_{2} \mathrm{CO}_{-}-t-\mathrm{Bu}$ and chiral ligand $5(5 \mathrm{~mol} \%)$ in refluxing THF for $3 \mathrm{~h}$, the dehydrated product ta was isolated in $49 \%$ yield $(59 \%$ conversion) and unconverted diastereomeric mixture of $\mathbf{2 a}$ and $3 \mathrm{a}$ was obtained in $29 \%$ combined yield. The $\mathrm{dr}$ of unreacted esters 2a and 3a was 70:30 as determined by analysis of the ${ }^{1} \mathrm{H}$ NMR spectrum of reaction mixture and enantiomeric excess (ee) was $98 \%$ for each one. With chiral ligand $\mathbf{5}$. both $\mathbf{2 a}$ and $3 \mathrm{a}$ were dehydrated at similar rates and kinetically resolved with similar efficiencies. producing the eliminated product $\mathbf{4 a}$ with $40 \%$ ee. These results reflect highly effective discrimination between $I^{\prime} S$ and $l^{\prime} R$ chiral center in dehydration, but little influence of the chiral center at 2-position.

To determine the stereochemical relationship of the diastereomers $\mathbf{2 a}$ and $3 \mathbf{a}$. we have carried out the reaction of the mixture of enantioenriched $(2 R)-2 \mathbf{a}$ and $(2 R)-3 \mathbf{a}$ under the same condition with chiral ligand $5^{6}{ }^{6}$ The chiral phase HPLC analysis of the reaction mixture indicates that $(2 R)-2 \mathrm{a}$ is a fast reacting enantiomer of $2 \mathbf{a}$. while $(2 R)-3 \mathbf{a}$ is a slow reacting enantiomer of 3a. Based on the assumption that the $l^{\prime}$ 'S enantiomer is dehydrated faster than $l^{\prime} R$ enantiomer with chiral ligand $5{ }^{7}$ the absolute configurations of slow reacting enantiomers of $\mathbf{2 a}$ and $3 \mathbf{a}$ are provisionally assigned as $\left(2 S .1^{\prime} R\right)$ and $\left(2 R, 1^{\prime} R\right)$ respectively as indicated in Scheme 1.

We here reported the highly diastereoselective Reformatsky reactions and successful cataly tic kinetic resolution of $\beta$ $(2 H$-3-flavenyl)- $\beta$-lydroxy esters in asymmetric elimination. To our knowledge. this is the first highly enantioselective method to prepare 3-alkenyl flavenes and 3-(1-hydroxyalkyl) flavenes containing two stereogenic centers. These products contain several functionalities that allow further transfonmations into more complex molecules. Further investigation of the scope of the asymmetric elimination with various $\beta$-( $2 H$-3-flavenyl)- $\beta$-hydroxy esters and its application to the syntheses of biologically interesting molecules is underway.

Acknowledgments. This work was supported by a grant from Korea Research Foundation (KRF-2006-005-J03402).

\section{References and Notes}

1. (a) Satoh, Y.: Stanton, J. L.; Hutchison. A. J; Libby: A. H; Kowalski, T. J. Lee. W. H.; White. D. H. Kimble, E. F. I. Med Chen 1993. 36. 3580. (b) Cheng. J.-F.: Ishikawa. A.: On1o. Y: Arrhenius. T.: Nadzant. A. Bioong Med. Chent Lett. 2003. 13. 3647. (c) Hajela. K.: Pandey. T.: Dwivedy. A.: Dhar. T. D.: Sarkhel, S.: Maulik. P. R.; Velumurugan, D. Bioorg. Hed Chem. 1999. 7. 2083. (d) Ishizuka. N.; Matsumura, K.-i.: Kikuchi, J:; Nakai. H. Bioorg. Med Chem 2002, 10,3965. (e) Funk, O. F: Kettmantr. V: Drimal. J.: Langer. T. J. Med Chem. 2004. 47. 2750. (t) Ishizuka. N.: Matsumura. K.-i.: Sakai. K.: Fujimoto. M.: Mihara. S.-i.: Yamamori. T. J. Med Chen 2002. 45. 2041.

2. (a) Sunden. H.: Ibrahem. I.: Zhao. G.L.: Eriksson. L.: Cordova. A. Chem. Eur J. 2007. 13, 574, (b) Li, H. Wang. J.: E-Nunu. T; Zu. L.: Jiang, W.: Wei, S.: Wang, W. Chem Commo 2007. 507 . (c) Govender. T.: Hojabri. L.: Moghaddam. F. M.: Arvidsson. P. I. Tetrahedron: Astmmtetry 2006. 17. 1763. (d) Konoike. T: Matsumura. K.-i.: Yorifuij. T.: Shinomoto. S.: Ide. Y.: Ohya. T. $J$. Org. Chem 2002, 67, 7741. (e) Hardouin. C.: Burgaud, L: Valleix, A.: Doris. E. Tetrahedron Lett. 2003, $4+435$.

3. (a) Robinson. D. E. J. E.: Bull, S. D. Tetahedron: Aswmeny 2003. 14 . 14(17. (b) Keith. J. M.: Larrow. J. F.: Tacobsont. E. N Ada: Smbl Catal. 2001. 3+3. 5. (c) Vedejs. E.: Daugulis. O. J.Am Chent Soc. 2003. 125.4166. (d) Tao. B.: Ruble. T. C.: Hoic. D. A.: Fu. G. C. J. Am. Chom Soc. 1999, 121, 5091. (e) Miller, S. J: Copeland, G. T.: Papaioannou, N.: Horstmann. T. E.; Ruel, E. M J. Am. Chem. Soc. 1998. 120, 1629. (f) Mazet. C.: Roseblade, S.; Kohler. V: Ptaltz. A. Org. Lett. 2006. 8. 1879. (g) Yamada. S.: Misono. T.: Iwai. Y. Tetrahedron Lett. 2005. +6. 2239. (h) Suzulki. Y: Yamauchi. K:: Muramatsu. K.: Sato. M. Chem. Contmtut. 2004. 2770 .

4. (a) Kim, Y.: Choi, E. T.: Lee, M. H.; Park. Y. S. Tetrahedron Lett. 2007. 18. 2833. (b) Choi. E. T.: Lee. M. H.; Kim. Y:: Park, Y. S. Tetrahedron 2008. 64. 1515 .

5. General pocedne for astmmetric delndration: Trimethylehlorosilane (0.5 equiv) was added to a suspension of zinc metal ( 8 equiv) in anhydrous THF. After the mixture was refluxed for 40 min. a solution of chiral ligand $\left(5 \mathrm{~mol}^{\circ} \mathrm{o}\right)$, tert-buttl bromoacetate (8 ecpuiv) and racemic 2a and $3 \mathbf{a}$ in THF was slowly added. The mixture was stirred at reflus for $2-6 \mathrm{~h}$ and then quenched with saturated $\mathrm{NH}_{4} \mathrm{Cl}$ aqueous solution. The resulting misture was extracted with $\mathrm{CH}_{2} \mathrm{Cl}_{2}(2 \cdot 5 \mathrm{~mL})$ and combined extracts were washed with brine. The solvents were removed under reduced pressure and the residue was purified by flash column chromatography to give enantioenriched flavene derivatives.

6. The enantioentiched $(2 k)-2 \mathrm{a}(80.20 \mathrm{er})$ and $(2 k)-3 \mathrm{a}(80.20 \mathrm{er})$ were prepared from Reformatsky reaction of $(k)$-flavene aldehyde 1a $(80: 20$ er). which was prepared by the kinowin procedure with a organocatalyst. $(S)$-diphenylpyrrolinol silyl ether. ${ }^{-2-c}$

7. We have previously reported that asymetric delydration of various $\beta$-aryl or alkenyl $\beta$-hydroxy $t$-butyl esters proceeds favoring (\$)-enantiomer in the presence of chiral ligand $\mathbf{5}^{4}$ 